\title{
Mundialização e o trabalho do ser social professor pesquisador
}

Globalization and work and social being research professor

\author{
João dos Reis Silva Junior* \\ Universidade Federal de São Carlos \\ Carlos Lucena** \\ Universidade Federal de São Carlos \\ Luciana Rodrigues Ferreira*** \\ Universidade Federal de São Carlos
}

Resumo Este artigo tenta analisar o movimento da dimensão do tempo contemporâneo na sociedade capitalista.Aexistência da humanidade no presente e suas prerrogativas, utopias, sonhos e desejos aponta o desafio da percepção de um conceito de tempo como uma construção cultural de base materialista. Esses são pressupostos utilizados para uma crítica radical às condições de trabalho na Instituição Universitária Pública Brasileira. A mundialização da economia, expressa pelo capital financeiro, redefine o conceito de tempo, acelerando-o aos interesses da reprodução desenfreada do capital, impondo processos perversos no cotidiano educacional responsáveis pelo crescimento do estranhamento no trabalho dos professores.

PALAVRAS-CHAVE: Tempo contemporâneo, Mundialização da economia, Intensificação do trabalho, Trabalho docente.

Abstract This article attempts to analyze the movement of the time dimension in contemporary capitalist society. The existence of humanity in the present and its prerogatives, dreams and desires show the challenge of understanding the perception of a concept of time as a cultural construction of base materialism. These are assumptions for a radical critique of working conditions in the Brazilian Public Higher Education Institution. The globalization of the economy expressed by finance capital redefines the concept of time, accelerating it to the interests of uncontrolled reproduction of capital, imposing evil in everyday educational processes responsible for estrangement growing in the work of teachers.

KEYWORDS: Contemporary time, Globalization of the economy, Intensifying work, Teaching. 
A nova configuração do capitalismo, que se inaugura nos anos 1970, transcende à internacionalização da economia: trata-se de sua mundialização. Segundo François Chesnais (1996), existem três dimensões principais para a realização desse processo: intercâmbio comercial, investimento produtivo no exterior e fluxos de capital monetário, ou capital financeiro. O autor acrescenta que "as relações entre essas três modalidades de internacionalização devem ser buscadas ao nível das três formas ou ciclos da movimentação do capital, definidos por Marx: o capital mercantil; o capital produtor de valor e de mais-valia; o capital monetário ou capital-dinheiro" (CHESNAIS, 1996, p. 51).

Citando Charles-Albert Michalet, Chesnais afirma que essa abordagem permite mostrar a passagem da internacionalização da economia, com base no comércio exterior e nos fluxos de capital monetário e financeiro, para a economia mundializada, por sua vez ancorada na mundialização do capital produtor de mais-valia. O aumento do investimento externo direto (IED) e as consequências qualitativas daí derivadas na reorganização das economias nacionais e mundial, especialmente nas grandes corporações transnacionais, provocam uma mudança no paradigma tradicional. Segundo Michalet citado por Chesnais (1996, p. 52), "No paradigma tradicional, o capital produtivo fica colocado por fora da mundialização do capital. A transformação da economia internacional em economia mundial coincide com o fim dessa dicotomia. A mundialização do capital produtivo tornase parte integrante da mundialização do capital. [...] mais exatamente, torna-se o centro dela."

Na década de 1980, especialmente em seu início, a mundialização do IED sofreu significativo aumento. No entanto, para além dos aspectos quantitativos do IED na economia mundial, seus aspectos qualitativos parecem realmente colocá-lo no centro da mundialização do capital. Emerge um novo paradigma de empresa, com novas estruturas corporativas, novas formas organizativas e de gestão, assentadas em nova base produtiva, possibilitadas pelas atuais tecnologias produzidas no âmbito da terceira revolução tecnológica. Afirma Chesnais (1996, p. 59-60), citando Michalet, a emergência de "multinacionais de novo estilo", em cujo centro encontra-se a estratégia tecno-financeira:

[...] de internacionalização baseada nos ativos intangíveis da companhia, no seu capital humano". E Michalet precisava: "A estratégia tecno-financeira é o resultado de uma evolução das atividades das companhias no exterior, passando da produção material direta para o fornecimento de serviços. A base de sua competitividade está alicerçada na definição de um know-how e na P\&D. Ela tentará valorizar essa vantagem em todos os setores onde for possível aplicar suas competências tecnológicas. Com isso, ela tenderá a sair do seu setor de origem e diversificarse em modalidades totalmente originais. Sua nova força reside em sua capacidade de montar 'operações complexas', [que] irão exigir a combinação de operadores vindos de horizontes muito diferentes: empresas industriais, firmas de engenharia, bancos internacionais, organismos multilaterais de financiamento. Destes, uns serão locais, outros estrangeiros, outros terão estatuto internacional. (grifos nossos) 
Citando Dunning (1988), Chesnais (1996, p. 77) complementa que essas corporações teriam, em seu centro identitário, a "natureza e forma das relações que estabelecem com outras empresas" e outras instituições fora da esfera econômica. No atual contexto da economia mundializada, ainda que o IED seja o centro dessa nova ordem econômica, a força do capital monetário ou financeiro faz-se presente na estruturação do novo paradigma corporativo acima descrito. $O$ capital financeiro torna-se hegemônico e o monetarismo assume o lugar da macro-gestão econômica, em nível mundial, influenciando largamente as estruturas das grandes companhias mundialmente organizadas e dos Estados nacionais e das instituições republicanas, com destaque nesse projeto para a instituição universitária pública, tornando altamente instável as sociedades nacionais e a irracionalidade, que viceja, em nível planetário.

Do afirmado acima, pode-se depreender que as fronteiras entre lucro e renda tornam-se cada vez mais fluidas, com consequências cada vez mais fortes para a consolidação do novo paradigma organizacional das grandes corporações em nível mundial, obrigando-as ao estabelecimento de relações mais consolidadas com outros grupos, empresas, etc.

Do que se pôde apreender acerca da forma como se estruturam e se organizam as empresas multinacionais de novo estilo ou as grandes corporações mundiais, elas:

1) atuam em nível mundial;

2) repassam, aos seus fornecedores, elementos da concepção e fabricação de componentes dos produtos, juntamente com know-how tecnológico, organizacional, gerencial, de processos de reengenharia, know-how de gestão de qualidade, etc., guardando a core organization para a corporação ou empresa multinacional de novo estilo (conhecimento objetivado em favor do capital). Promovem e financiam a transformação dos fornecedores. Constituem, a partir daí, uma relação de parcerias que lhes proporcionam vantagens, não por meio da comercialização de seus produtos ( $p$. ex, descontos em componentes de seus produtos, por tempo indeterminado, apropriação de produto de pesquisas realizadas em instituições no âmbito econômico ou em institutos de pesquisa e instituições universitárias), mas de seu know-how, nas diversas áreas de trabalho, vascularizando o processo e tornando-se mais rentáveis;

3) desenvolvem atividades de rental service;

4) reestruturaram-se, nos anos 1980, por meio do IED;

5) estabelecem, por meio de parcerias, compras, fusões e joint-ventures, redes, buscandoobtervantagensemsuasrelaçõescomasoutrasempresas, como organizações e instituições governamentais e universidades, estas, de forma acentuada no segundo mandato de governo do presidente Lula, e em continuidade no governo da presidente Dilma Rousseff.

As empresas multinacionais de novo estilo tornam-se o eixo condutor da economia mundializada, sob a gestão monetária e a hegemonia do capital financeiro. Este último parece produzir nova geoeconomia da produção de valor que atravessa e põe-se em torno do capital produtivo mundializado. Sua 
rentabilidade mundial é o objetivo maior. Como já visto, as corporações buscam vantagens predominantemente nas relações com empresas e instituições nacionais, internacionais ou multilaterais. Aqui se encontra a origem das reformas institucionais públicas realizadas nas décadas de 1980 e 1990.

Neste contexto do Brasil em Reforma, as universidades públicas são colocadas em posição estratégica. A autonomia universitária em geral, especificamente a científica, a indissociabilidade entre ensino, pesquisa e extensão, passam, gradativamente, a ter sustentação numa equação em que a demanda econômica torna-se a diretriz das investigações. Ao governo cabe criar as condições de financiamento e de reconstrução da identidade da instituição universitária para que ela se transforme em agência executora de tais demandas.

Por outro lado, ao anunciar a multinacional de novo estilo, Michalet (apud CHESNAIS, 1996, p. 76-77), argumenta acerca dos seus capitais intangíveis, destacando o capital humano. Continua ele, afirmando que a "[...] estratégia tecno-financeira é o resultado de uma evolução das atividades das companhias no exterior, passando da produção material direta para o fornecimento de serviços". (grifos nossos). Enfatiza Michalet que a contribuição de sua força econômica e de competitividade encontram-se em seu próprio know-how e na P\&D. Aqui, parece estar a chave para o entendimento das práticas institucionais cotidianas da universidade pública: a produção do capital humano e do estranhamento do ser social professor das instituições educacionais. Em razão dessa diretriz histórica, a educação básica, profissional e superior, com destaque para a pesquisa aplicada, a força de trabalho superqualificada e a produção de conhecimento são centrais. O processo de investigação é cautelosamente administrado pelos processos de avaliaçãoe cronogramas de desembolso do financiamento, solicitado pelo professor pesquisador. Nesta prática de pesquisa, ele naturaliza esse tempo. Mas qual é este tempo que se pode culturalmente qualificar?

\section{Racionalidade do tempo contemporâneo}

A Mobit (Mobilização Brasileira para a Inovação) produziu estudo sobre política industrial e de inovação de forma comparativa, liderado pelo sociólogo Glauco Arbix, coordenador da Mobit e do Observatório de Inovações e Competitividade, sediado no Instituto de Estudos Avançados da Universidade de São Paulo. O estudo foi encomendado a estes atores e suas mantenedoras, pela Agência Brasileira de Desenvolvimento Industrial e executado pelo Centro Brasileiro de Análise e Planejamento (Cebrap). Segundo Arbix, todos os países:

[...] dão à inovação o status de fator mais importante de suas estratégias competitivas, engajando atores como o meio empresarial, as universidades e o governo. "Cada um a sua maneira, esses países [Estados Unidos, França, Canadá, Irlanda, Reino Unido, Finlândia e Japão] caminharam para um paradigma em que o conhecimento ocupa lugar central na reprodução de novas relações econômicas e sociais". (MARQUES, 2008, p. 34). 
A preocupação é a de incorporar o que de melhor está sendo feito no mundo. Arbix afirma que:

\begin{abstract}
Uma das características marcante é o lugar atribuído às empresas nessas estratégias. O setor privado tem um papel central. Todos os esforços estão orientados para aperfeiçoar as atividades de pesquisa, desenvolvimento e inovação no ambiente empresarial. Há consenso de que é através da empresa que a economia irá movimentar-se e gerar bem-estar econômico. Nos sete países pesquisados as universidades são pressionadas a colaborar. [diz Arbix] "Não se trata de discutir sua autonomia, mas sim a relevância de sua pauta de pesquisa. As universidades são estimuladas a se adaptar às mudanças para ajudar as empresas". (ARBIX Apud MARQUES, 2008, p. 34)
\end{abstract}

Na matéria de Marques (2008) na revista Pesquisa FAPESP (n.147, mai, 2008, p. 34-36), outro ponto se destaca que tem sido recorrente no Brasil nestes últimos 14 anos, e que consiste na perenidade dessas estratégias e ações entre universidade, governo e empresa. Nos dois mandatos de Bush, nada mudou em relação aos oito anos do Governo Clinton quanto a este paradigma. Tudo indica a existência de consenso em relação a estas estratégias, mesmo entre partidos e governos muito diferentes ou até antagônicos. O mesmo se pode dizer da Inglaterra e da Finlândia, que já fazem isto há décadas; a Irlanda institucionalizou sua "Social Partnership" em 1987. Isto é muito significativo no mundo atual, com consequências de natureza identitária. Isso implica dizer que a universidade está profundamente mudada nas suas estruturas institucionais e na sua autonomia. Formas de gestão políticas acadêmicas e científicas estão postas desde seu exterior, bem como a avaliação se realiza por resultados e sua acreditação pela "relevância de sua pauta de pesquisa". Aqui, o tempo decorrente dos novos processos de controle e regulação sociais, acadêmico e econômico se identifica, na instituição universitária pública, constituindo-se em sua nova cultura a orientar as práticas cotidianas dos professores pesquisadores, que as incorporam e reproduzem, contraditoriamente, formando a si mesmos. Começam a ser mais explícitos e muito concretos os processos de estranhamento do trabalho docente e do resultado de seu trabalho, que sem significado para o professor da universidade, não lhe faz sentido. Conquanto, estranha a si mesmo. Uma das decorrências mais frequentes deste processo amplia e intensifica o processo de adoecimento dos docentes.

Nesses países, como se pôde inferir, a formação de intelectuais, em sentido estrito deverá ser ínfima, pois essas universidades formariam, predominantemente, profissionais cujas ações e sociabilidade estão voltadas para a empresa, tomadas como a ponta de lança para o crescimento econômico. Neste ponto, pode-se dizer que a defesa de Hayek, da concretude das atividades humanas orientadas pela lógica mercantil, se concretiza, na universidade, em que o intelectual típico dessa instituição ainda não mercantilizada cede lugar ao professor pesquisador profissional. Neste movimento, o professor em sua prática institucional transforma o seu ser social no processo de incorporação e objetivação da culturaç, que hoje, preside a universidade pública no Brasil. Em depoimento 
a Sguissardi e Silva Júnior (2009) um professor, de uma universidade da região sudeste brasileira, revelou que a dimensão cultural e econômica do tempo e a modificação da ciência e do ser social pesquisadores:

Meu orientador teve os seus defeitos, mas teve enormes qualidades, ele me ensinou que ciência não se faz com pressa! Ciência não se faz por encomenda! Ciência não se faz com horário marcado! E esse é o modelo de hoje. Hoje um aluno tem que entrar... com dois anos pra fazer mestrado, ele tem que fazer o curso, cumprir os créditos, fazer o projeto, realizar e executar o projeto, escrever a sua tese e escrever um trabalho pra publicar em revista de nível internacional e não sei o quê. Em dois anos! Quer dizer que você tem que publicar um trabalho em quatro anos que é o doutorado. Aí são dois trabalhos publicados. Então isso tem feito o quê? Tem feito cair a qualidade da ciência. - Aí a paixão se torna um pouco droga, porque o humano tem limite. O humano tem limite com certeza (...) Foi uma coisa que o meu orientador me ensinou e o primeiro que me ensinou isso foi meu pai. Meu pai, no dia que eu decidi e falei pra ele como que era o curso de Ciências Biomédicas (meu pai é formado pela Escola Politécnica da França): “Olha, você vai fazer pesquisa, não vão te passar uma letra. Quando você for fazer ciência faça tudo pra você provar, você provar que você está errada! Caso você não consiga, você talvez diga que você estava certa". É uma atitude totalmente diferente da de hoje em que eu sou obrigada, eu sou obrigada! A Fapesp me obriga, o CNPq me obriga, a Finep me obriga, todas as financiadoras obrigam que você tem que publicar um trabalho dentro de dois anos e pouco, dentro de um ano, dois trabalhos por ano, três trabalhos por ano.E as revistas valem peso. E esse é um outro questionamento que eu faço, porque se exige publicação internacional. $O$ interesse dos problemas internacionais não são os nossos interesses, absolutamente não são! Então, quando me obrigam a publicar num Qualis não sei das quantas nos EUA ou na Europa, eu estou publicando, mas estou resolvendo problemas deles! E não da realidade nossa. Então isso é uma distorção gravíssima no meu modo de ver, porque obriga você a fazer ciência pra eles e no tempo deles, eu me questiono aqui o tempo todo: "O que adianta você publicar 20 trabalhos lá na América, lá na revista lá em cima? O que isso trouxe de benfeitoria pro Brasil? Pro povo brasileiro?". É isso que eu quero saber!

O tempo da produção da ciência, da formação do pesquisador e do processo de trabalho de investigação é marcado pela racionalidade econômica e provoca o estranhamento do professor pesquisador em relação ao seu trabalho, ao produto de seu trabalho e em relação a si mesmo. Por outro lado, existimos objetivamente na relação com o contexto de nosso tempo histórico e existimos no plano de nossa consciência como resultado de nossa percepção, de nossos sentidos e do processo de conhecimento sistematizado ou não. Isso produz uma distância entre estes dois pólos: a existência objetiva e a representação em nossa consciência. Quanto maior for essa distância, maior será a possibilidade de nos 
frustrarmos em nossas práticas cotidianas. Na universidade, maior a possibilidade de nos estranharmo-nos a nós mesmos, em razão dos tempos acadêmicos, empresariais, sociais e os da esfera privada de cada professor se encontrar de superpostos no cotidiano e condensadamente formando a nova cultura dessa instituição republicana.

Esta dimensão de "migração" do "tempo da produção" para o "tempo científico" e para o "tempo da vida" requer severa crítica em termos da problematização do sentido da produção de mercadorias sob a lógica da reprodução do capital. O tempo da produção toma uma dimensão de eficiência de cunho fetichista, omitindo os projetos e visões de mundo da classe que os concebe. Itsvan Mészáros em "O desafio e o fardo do tempo histórico" demonstra que o tempo de vida, tanto dos indivíduos, quanto da humanidade se subordina ao imperativo do tempo reificado do capital, independente de suas consequências. Os desdobramentos da reprodução sociometabólica do capital determinam a degradação do tempo, visto que a condição objetiva para a sua auto-expansão tem como condicionante a exploração crescente do tempo trabalho. "O capital, portanto, devetornar-secego com relaçãoa todas as dimensões dotempo diversas da dimensão relativa ao trabalho excedente explorado ao máximo e o correspondente tempo de trabalho". (MÉSZÁROS, 2007, p. 33)

É ainda altamente relevante que o corpo social mais abrangente ao qual os indivíduos pertencem desenvolve historicamente a humanidade, com seu tempo de vida incomparavelmente mais extenso que o dos indivíduos particulares. O tempo histórico da humanidade transcende o tempo dos indivíduos - trazendo consigo a dimensão mais fundamental do valor - mas mantendose, ao mesmo tempo, em sentido dialético, como inseparável dele. (MÉSZÁROS, 2007, p. 34-35)

Mészáros debate as contradições entre o tempo da humanidade e o dos indivíduos, demonstrando que a relevância da discussão se justifica por uma formação objetiva do valor e do contra-valor, acrescentado do tempo contra o tempo que se reflete na formação do ser social em geral, em particular no ser social professor pesquisador. A instituição de valor, baseada na relação objetiva entre a escala temporal radicalmente diferente dos indivíduos particulares e da humanidade, é uma parte essencial desse processo de progressão histórica. A contestação do valor é, e sempre será, um órgão vital do desenvolvimento da sociedade. "O tempo efetivamente dado da história dos séculos XX e XXI alcançou tanto os indivíduos como a espécie. Ainda mais porque algumas tecnologias produtivas poderosas e o uso potencial ao qual elas podem ser postas trazem consigo a necessidade de tomar decisões difíceis e perigosas, que envolvem diretamente a questão do tempo" (MÉSZÁROS, 2007, 38).

Para Mészáros, as diferenças entre os interesses da humanidade e a dos indivíduos manifestam-se nas ações para a reprodução do capital existentes na sociedade. Os desdobramentos inventivos expressos pela ciência implicam em 
ações de classe, que pouco se importam com os desdobramentos sociais de seus inventos. O que está em jogo é a reprodução do capital, não importando as ações para isso, sendo a energia nuclear para fins militares um exemplo. $O$ capital se apropria do tempo livre da sociedade, construindo imperativos para esse fim. $O$ tempo livre, desprovido de sentido para o capital, deve ser convertido, subvertido, degradado, com o objetivo de submetê-lo, exploradamente, ao imperativo global da acumulação do capital. O contra-valor lucrativo deve ditar a medida em consonância com o tipo historicamente dominante da contabilidade do tempo capitalista, em conjunção com a necessidade cada vez mais anacrônica de redução do tempo de trabalho ao mínimo necessário, inseparável da redução alienante dos próprios seres humanos à carcaça do tempo.

Como afirmamos, o empobrecimento do conteúdo do trabalho traz sérios desdobramentos àqueles que dele sobrevivem, merecendo destaque o professor pesquisador. A exposição por tempo longo ao estranhamento leva ao profundo sofrimento e em consequência ao adoecimento em diversas formas, com ênfase para as relacionadas à saúde mental. Nosso trabalho, em vez de fruição, tornase o simulacro da fruição. Traz-nos um falso prazer, exatamente como qualquer outro tipo de vício. De pronto, nos traz um falso prazer e, a médio e longo prazo, nos cobra por meio do sofrimento e do adoecimento. O tempo econômico, no universo do trabalho estranhado, atua contra o próprio homem. Nesse sentido afirma Lukacs:

A objetividade do valor econômico está fundada na essência do trabalho como intercâmbio orgânico entre sociedade e (natureza) e, no entanto, a realidade objetiva do seu caráter de valor vai além deste nexo elementar. A própria forma original do trabalho, para a qual a utilidade fixa o valor do produto, mesmo que se relacione diretamente com a satisfação da necessidade, põe em movimento, no homem que o realiza, um processo, cuja intenção objetiva - independente do grau de consciência - está voltada para o ulterior desenvolvimento do homem. Desse modo, há, no valor econômico, uma elevação qualitativa com respeito ao valor que já existia na atividade simples, produtora de valor de uso. Temos, assim, um movimento duplo e contraditório: de um lado, o caráter de utilidade do valor adquire uma dimensão de universalidade, de domínio sobre o conjunto da vida humana e isto acontece ao mesmo tempo em que a utilidade vai se tornando cada vez mais abstrata, na medida em que o valor de troca, sempre mediado, elevado à universalidade e em si mesmo contraditório, assume a função de guia nas relações sociais entre os homens. Sem que com isso se possa esquecer que o pressuposto para a existência do valor de troca é o valor de uso. O elemento novo contraditório, dialético, das determinações originárias, já presentes na gênese e não a sua simples negação abstrata. De um lado, esse desenvolvimento, responsável por formações realmente sociais como o capitalismo e o socialismo, é em si mesmo contraditório, o que é extremamente importante e fecundo: a sociabilidade desenvolvida da produção resulta num sistema imanente, que repousa em si mesmo, fechado em 
si mesmo, com respeito ao econômico, no qual uma práxis real só é possível na medida em que esteja orientada para finalidades econômicas imanentes e para a correlativa busca dos meios. Com efeito, a expressão homo economicus não surge por acaso e muito menos por equívoco; ela representa em termos adequados e plásticos o comportamento imediato do homem em um mundo onde a produção se tornou social. Mas apenas o comportamento imediato. Com efeito, tanto no capítulo sobre Marx, como nas presentes considerações, fizemos questão de deixar claro que não podem existir atos econômicos - desde o trabalho originário até a produção social pura - sem intenção, ontologicamente imanente, voltada para a humanização do homem no sentido mais amplo do termo, ou seja, que diz respeito tanto à sua gênese quanto ao seu desenvolvimento. Essa constituição ontológica da esfera econômica ilumina a sua relação com os outros domínios da práxis humana. (1981, p. 74)

Em outro depoimento, o tempo na construção do ser social professor pesquisador mediado pela sua prática institucional orientada pelo tempo econômico se apresenta de forma explícita.

\begin{abstract}
Uma coisa que eu sempre costumo falar, é que a pessoa, quando é pesquisadora, é quase como um distribuidor de droga, porque isso pega. E eu acho que o pessoal que lida com isso sabe dessa verdade, então usa e abusa da gente por causa disso. Porque você só faz ciência realmente se tiver uma paixão fora de série, porque é uma profissão que exige muito tempo da vida. Exige você sair fora um pouco da sua família porque você não tem um horário de trabalho, o trabalho avança, avança à noite na sua casa. Você leva artigos pra ler, você leva relatório pra ler, você está o tempo todo com a sua cabeça tentando responder aquela pergunta ou aquele questionamento que você está interessado em resolver. É isso que você faz com paixão. Eu costumo falar isso para os meus alunos: "Acabou o trabalho! Não é mais trabalho! É uma paixão" Ou droga também. Pois é, é desse lado da droga, no sentido de que, quando a pesquisa pega em você, fica muito difícil você abandonar a pesquisa, é muito difícil. Então você suporta as piores condições, porque o prazer de achar algo novo, o prazer de você estar destrinchando, abrindo fronteiras é algo que não tem preço e não tem o que cubra isso, não há dinheiro nenhum que cubra isso, não é? Então você acaba fazendo nas piores condições e, nas piores condições, você continua fazendo.
\end{abstract}

Mészáros tece considerações sobre essa questão apontando a urgência e centralidade da luta pela emancipação social. Uma das conquistas mais importantes da humanidade está na forma do tempo livre potencialmente emancipatório, incorporado no trabalho excedente, produtivamente crescente na sociedade, precondição e tesouro promissor de todo avanço futuro, se libertado do seu invólucro capitalista alienante. Essa conquista, no entanto, foi forçada a vestir camisa de força fundamentalmente sufocante da mais-valia, sob o corolário do imperativo de reduzir ao mínimo o tempo, de trabalho necessário, de modo a 
ser manipulado pela contabilidade do tempo não apenas desumanizadora, mas também, em termos históricos, cada vez mais anacrônica do sistema. Isto é o traço central da nova cultura da universidade pública atual. A emancipação humana é plausível apenas com base em uma concepção histórica que rejeita, não apenas a ideia do determinismo materialista mecânico, mas também o tipo de desfecho da história filosófico idealista que encontramos na monumental visão hegeliana do mundo. Porém, essas ações não devem ser naturalizadas. Para Mészáros, o que é historicamente criado pelos indivíduos pode ser historicamente mudado por esses mesmos indivíduos. A condição da emancipação passa pelo engajamento dos homens nos processos de superação da sociedade. Nem sempre, o tempo histórico dos indivíduos deve conflitar com o da humanidade. É possível também construir a harmonia entre ambos. Para isso, as alternativas viáveis são a construção e um futuro sustentável da humanidade, condição fundamental para a sobrevivência humana. (MÉSZÁROS, 2007, 43-49)

A nós, professores pesquisadores das universidades brasileiras, apresentase a seguinte questão: imaginarmo-nos em um universo fenomênico, cuja essência é o eugenismo entre os pares manifesto no imperativo da produtividade irrestrita como critério de eficiência ou, resistirmos, tal qual exemplificou a greve das IFES em 2012, entendendo-nos como existentes em um mundo material movido, historicamente, pela luta de classes e os antagonismos por ela criados. Como bem afirmou Marx e a "Ideologia Alemã", inverter o mundo de "cabeça para baixo" nos parece a opção...

\section{Referências}

CHESNAIS, F. A mundialização do capital. São Paulo: Xamã Editora, 1996.

FURTADO, C. Criatividade e dependência na civilização industrial. São Paulo: Companhia das Letras, 2008.

HARVEY, D. Condição pós-moderna. São Paulo. Edições Loyola, 1982.

Condição Pós-moderna. São Paulo: Edições Loyola, 1989.

LUCENA, C. Hayek, liberalismo e formação humana. Campinas: Alínea, 2010.

LUKÁCS, G. Estética, v. 1. Barcelona, Grijalbo, 1974.

Ontologia do ser social: os princípios ontológicos fundamentais de Marx. São Paulo, Ciências Humanas. 1979.

LUKÁCS, G. Trabalho. In: Per una ontologia dell'essere sociale. Roma: Ed. Riuniti, 1981, tradução de Ivo Tonet, UFAL, Paraíba

MARQUES, F. Lições Inovadoras. Pesquisa FAPESP, São Paulo, n. 147, mai/2008, p. 34-36.

MARX, K. Grundisse. In: MARX K. Obras Completas: consequências sociais do avanço tecnológico. Edições Populares, São Paulo, 1980.

MARX, K., ENGELS, F. Manifesto Comunista. São Paulo: Boitempo Editorial,1998.

MARX, K. O Capital: crítica da economia política. Livro 1, v. I, tradução Regis Barbosa e Flávio R. Kothe. 2. ed., São Paulo: Nova Cultural, 1985. 
MARX, K.; ENGELS, F. A Ideologia Alemã. Trad. Castro e Costa, L. C. São Paulo: Martins Fontes, 2002.

O Capital: crítica da economia política. Livro 3, v. VI, tradução Reginaldo Sant’ Anna 3. ed., Nova Cultural, São Paulo, 1984.

O Capital: crítica da economia política. Livro 1, v. II, tradução Regis Barbosa e Flávio R. Kothe. 3. ed., São Paulo: Ed. Nova Cultural, 1988.

MÉSZÁROS, I. O desafio e o fardo do tempo histórico. São Paulo: Boitempo Editorial, 2007. SGUISARRDI, V.; SILVA JÙNIOR, J. dos R. Trabalho intensificado nas federais: pósgraduação e produtivismo acadêmico. São Paulo: E JR Xamã, 2009.

* Professor Doutor da Universidade Federal de São Carlos, Centro de Educação e Ciências Humanas, Departamento de Educação e do Programa de Pós-Graduação em Educação. Bolsista de Produtividade do CNPQ nível 1D. São Carlos, São Paulo, Brasil.

** Professor Doutor da Universidade Federal de Uberlândia, Faculdade de Educação. Uberlândia, Minas Gerais, Brasil.

*** Doutoranda em Educação no Programa de Pós-Graduação em Educação da Universidade Federal de São Carlos, São Carlos, São Paulo, Brasil.

\section{Correspondência}

João dos Reis Silva Júnior - Universidade Federal de São Carlos, Centro de Educação e Ciências Humanas, Departamento de Educação. Rodovia Washington Luiz, Km 235, Centro, CEP: 13565-905 - Sao Carlos, São Paulo, Brasil. Caixa-postal: 676

E-mail: carloslucena@centershop.com.br

Recebido em 21 de março de 2013

Aprovado em 27 de julho de 2013 
